\title{
Profiling the unique protective properties of intracranial arterial endothelial cells
}

\author{
Dorien M. A. Hermkens ${ }^{1 *}$ D, Olga C. G. Stam ${ }^{1 \dagger}$, Nienke M. de Wit ${ }^{2 \dagger}$, Ruud D. Fontijn², Aldo Jongejan ${ }^{3}$, \\ Perry D. Moerland ${ }^{2}$, Claire Mackaaij ${ }^{1}$, Ingeborg S. E. Waas ${ }^{1}$, Mat J. A. P. Daemen ${ }^{1}$ and Helga E. de Vries ${ }^{2}$
}

\begin{abstract}
Cardiovascular disorders, like atherosclerosis and hypertension, are increasingly known to be associated with vascular cognitive impairment ( $\mathrm{VCl}$ ). In particular, intracranial atherosclerosis is one of the main causes of $\mathrm{VCl}$, although plaque development occurs later in time and is structurally different compared to atherosclerosis in extracranial arteries. Recent data suggest that endothelial cells (ECs) that line the intracranial arteries may exert anti-atherosclerotic effects due to yet unidentified pathways. To gain insights into underlying mechanisms, we isolated post-mortem endothelial cells from both the intracranial basilar artery (BA) and the extracranial common carotid artery (CCA) from the same individual (total of 15 individuals) with laser capture microdissection. RNA sequencing revealed a distinct molecular signature of the two endothelial cell populations of which the most prominent ones were validated by means of qPCR. Our data reveal for the first time that intracranial artery ECs exert an immune quiescent phenotype. Secondly, genes known to be involved in the response of ECs to damage (inflammation, differentiation, adhesion, proliferation, permeability and oxidative stress) are differentially expressed in intracranial ECs compared to extracranial ECs. Finally, Desmoplakin (DSP) and Hop Homeobox (HOPX), two genes expressed at a higher level in intracranial ECs, and Sodium Voltage-Gated Channel Beta Subunit 3 (SCN3B), a gene expressed at a lower level in intracranial ECs compared to extracranial ECs, were shown to be responsive to shear stress and/or hypoxia. With our data we present a set of intracranial-specific endothelial genes that may contribute to its protective phenotype, thereby supporting proper perfusion and consequently may preserve cognitive function. Deciphering the molecular regulation of the vascular bed in the brain may lead to the identification of novel potential intervention strategies to halt vascular associated disorders, such as atherosclerosis and vascular cognitive dysfunction.
\end{abstract}

Keywords: Vascular cognitive impairment, Intracranial vasculature, Endothelial cells, RNA sequencing

\section{Introduction}

Cardiovascular diseases (CVD) such as atherosclerosis, hypertension and heart failure are all associated with an increased risk of vascular cognitive impairment (VCI). CVD can influence cerebral perfusion and may also lead to development of white matter lesions, blood-brainbarrier dysfunction, cerebral microbleeds, brain atrophy and neuro-inflammation $[16,17,65]$. Interestingly, improvement of heart function or lowering of blood pressure is known to stimulate cognitive functioning [11, 23, 42]. Therefore, the key to successful therapeutic intervention

\footnotetext{
* Correspondence: d.m.hermkens@amsterdamumc.nl

${ }^{\dagger}$ Olga Stam and Nienke de Wit contributed equally to this work.

'Department of Pathology, Amsterdam UMC, University of Amsterdam,

Amsterdam Cardiovascular Sciences, Meibergdreef 9, Amsterdam,

Netherlands

Full list of author information is available at the end of the article
}

in VCI requires detailed understanding of the underlying cardiovascular mechanisms.

One of the main causes of VCI is atherosclerotic plaque formation in the vessel wall $[4,5,36,63]$. Atherosclerosis is the most well-known disease of the arteries and is known to manifest itself differently in intracranial arteries compared to extracranial arteries. In humans, intracranial atherosclerosis develops approximately 20 years later than extracranial atherosclerosis [57]. Furthermore, intracranial atherosclerotic plaques are less advanced and less vulnerable to plaque rupture and intraplaque hemorrhages, compared to extracranial atherosclerotic plaques [31, 33, 44], suggesting a reduced susceptibility of intracranial arteries to systemic risk factors for atherosclerosis. However, current research on $\mathrm{VCI}$ is focused on the vasculature in general (recently

(c) The Author(s). 2019 Open Access This article is distributed under the terms of the Creative Commons Attribution 4.0 International License (http://creativecommons.org/licenses/by/4.0/), which permits unrestricted use, distribution, and 
reviewed in [14, 26]) and does not describe the specific role of the intracranial arteries.

Endothelial cells (ECs) form a single cell layer that lines all blood vessels and regulates exchange between the bloodstream and surrounding tissues. Intracranial ECs display an increased antioxidant enzyme activity and a strong blood-brain-barrier that protect the brain vasculature and the underlying brain parenchyma from disease development [9]. To unravel the role of intracranial ECs in cerebral vascular functioning on a molecular level, several studies have analyzed the transcriptome of brain microvascular ECs, mostly in mice [20, 24, 28, 32, 48, 60]. So far, only a limited number of studies describing the transcriptome of human astrocytes, microglia, neurons, oligodendrocytes, pericytes and endothelial cells has been performed $[8,52,56,66]$. To date, all studies on human brain samples are focused on the microvasculature of the brain. Although the larger intracranial arteries are key in atherosclerotic plaque formation and consequently VCI development, data on the transcriptome of the ECs of the intracranial arteries are lacking. Uncovering the endothelial mechanisms that contribute to intrinsic atheroprotective properties and thus to lowering of the local intracranial atherosclerotic plaque burden, might be key to healthy cerebral vascular functioning.

With our study we are the first to unravel the distinct molecular pathways of intracranial artery endothelial cells in humans in order to identify novel pathways possibly involved in the protective nature of these ECs in the development of atherosclerosis and VCI. The paired comparison of the ECs derived from the intracranial artery as well as from the extracranial artery has to our knowledge not been performed before and will be addressed here. The identification of protective pathways in the vascular bed of the brain is a first step towards novel early intervention strategies to counteract brain endothelial associated diseases like atherosclerosis and VCI.

\section{Materials \& methods \\ Patient material}

We obtained post-mortem samples from the common carotid artery (CCA) and the basilar artery (BA) from 15 individuals, who were autopsied at the Amsterdam UMC in the period between February 2015 and July 2016. Inclusion criteria were 1) all individuals were adults, 2) time between death and autopsy (post-mortem delay, PMD) was less than $72 \mathrm{~h}$ and 3) written permission to obtain the materials at autopsy for research purposes was granted by the family of the patients. Age, gender, cause of death and PMD were documented in Table 1. The criteria for the code of proper secondary use of human tissue in the Netherlands were met [Human tissue and medical research: code of conduct for responsible use. Federation of Dutch Medical Scientific Societies]. During autopsy the circle of Willis and the carotids were exposed and macroscopically normal parts of the CCA and BA were sampled. The materials were stored in containers and frozen immediately using liquid nitrogen. After autopsy the samples were stored in a freezer at $-80^{\circ} \mathrm{C}$.

Table 1 Patient characteristics with patient age, sex, cause of death and post-mortem delay. Patient 1-9 were used for RNA sequencing, patient 10-15 for biological validation. The cause of death of 4 patients is unknown, since the arteries for the study were donated anonymously and only age, gender and post mortem delay were available

\begin{tabular}{lllll}
\hline Patient number & Age (years) & Sex (male/female) & Cause of death & Post mortem delay (hours) \\
\hline 1 & 60 & $\mathrm{~m}$ & ALS & $<24$ \\
2 & 59 & $\mathrm{~m}$ & ALS & $<12$ \\
3 & 78 & $\mathrm{~m}$ & unknown & $<6$ \\
4 & 87 & $\mathrm{f}$ & Stroke & $24-48$ \\
5 & 65 & $\mathrm{f}$ & ALS & $24-48$ \\
6 & 62 & $\mathrm{f}$ & ALS & $24-48$ \\
7 & 66 & $\mathrm{f}$ & ALS & $24-48$ \\
8 & 32 & $\mathrm{~m}$ & unknown & $<24$ \\
9 & 68 & $\mathrm{~m}$ & ALS & $<24$ \\
10 & 69 & Sepsis & $24-48$ \\
11 & 68 & $\mathrm{f}$ & Pneumonia & $48-72$ \\
12 & 46 & $\mathrm{f}$ & Peritonitis & $48-72$ \\
13 & 85 & $\mathrm{f}$ & Stroke & $48-72$ \\
15 & 88 & $\mathrm{f}$ & Unknown & $<24$ \\
\hline
\end{tabular}




\section{Cryosectioning and hematoxylin staining}

The artery specimen were embedded with Tissue Tek (Tissue-Tek O.C.T Compound, Sakura) and liquid nitrogen on cryomolds. The membrane slides (MembraneSlide 1.0 PEN, Carl Zeiss Microscopy $\mathrm{GmbH}$ ) were pretreated with UV light for $15 \mathrm{~min}$. Frozen sections of $8 \mu \mathrm{m}$ were cut and mounted on the slides. The slides were stored at $-80^{\circ} \mathrm{C}$. To enhance the visibility of the $\mathrm{EC}$, the frozen sections were stained with hematoxylin (Mayer's hematoxylin Solution, Sigma Aldrich). To prevent the slides from defrosting, the hematoxylin, ethanol solutions and xylene were precooled. The slides were stained and dehydrated with graded ethanol solutions (75, 95 and 100\%) ending with xylene. Afterwards the slides were allowed to dry for a maximum of $5 \mathrm{~min}$ in the hood. The stained slides were stored at $-80^{\circ} \mathrm{C}$.

\section{Laser capture microdissection}

Laser capture microdissection (LCM6, Leica) was used to isolate the endothelial cells. At a 100x magnification the arteries were scanned for areas were the endothelial lining was intact and at 200x magnification the areas were selected for laser dissection. Areas which showed inflammation or accumulation of macrophages were excluded. In order to prevent the laser beam from damaging the EC layer, the cut was made directly underlying the luminal ECs. Damaged endothelium, defined as a non-continuous endothelial layer, was excluded. The samples were collected in extraction buffer (PicoPure RNA isolation kit (ThermoFisher) in a RNA-free microcentrifuge tube.

\section{RNA isolation and CDNA amplification}

RNA isolation was performed using the PicoPure RNA isolation kit (ThermoFisher) using the manufacturers' instructions. After incubating for $30 \mathrm{~min}$ at $42{ }^{\circ} \mathrm{C}$, the sample was centrifuged at $800 \mathrm{x}$ g for $2 \mathrm{~min}$ and stored at $-80^{\circ} \mathrm{C}$. Ethanol $(70 \%)$ was added in a $1: 1$ ratio to the cell extract. For optimal precipitation, samples were stored for $30 \mathrm{~min}$. at $-20^{\circ} \mathrm{C}$ before adding to the purification column. DNAse treatment was performed on the purification column. RNA was eluted in a volume of $11 \mu \mathrm{l}$. For cDNA synthesis we used the Ovation ${ }^{\circ}$ RNASeq System V2 (Nugen) using the manufacturers' instructions. Purification of SPIA cDNA was performed with the QIAquick PCR Purification Kit (Qiagen).

\section{RNA sequencing}

RNA sequencing was performed by Service XS (GenomeScan) using the Illumina Next Generation Sequencing Technology. The NEBNext ${ }^{\oplus}$ Ultra II DNA Library Prep kit for Illumina (cat\# NEB \#E7645S/L) was used to process the samples. Fragmentation of the DNA using the Biorupor Pico (Diagenode), ligation of sequencing adapters, and PCR amplification of the resulting product was performed according to the procedure described in the NEBNext Ultra DNA Library Prep kit for Illumina Instruction Manual. The quality and yield after sample preparation was measured with the Fragment Analyzer. The size of the resulting product was consistent with the expected size of approximately $500-700$ base pairs. Clustering and DNA sequencing using the Illumina NextSeq500 was performed according to manufacturer's protocols. A concentration of $1.6 \mathrm{pM}$ of library was used. NextSeq control software 2.2.0 was used. Image analysis, base calling, and quality check was performed with the Illumina data analysis pipeline RTA v2.4.11 and Bcl2fastq v2.20.

\section{RNA sequencing data analysis}

A dataset with a mean of $1.9 \mathrm{~Gb}$ (25.8 million reads) of Illumina-filtered single end 75 base pairs sequence data was generated per sample. Data analysis was performed using R (v3.3.1) and Bioconductor (v3.4). Raw sequencing data were subjected to quality control using FastQC (https://www.bioinformatics.babraham.ac.uk/projects/ fastqc/), dupRadar [50], Picard Tools (http://broadinstitute.github.io/picard/) and trimmed using Trimmomatic (v0.32; http://www.usadellab.org/cms/?page=trimmomatic). Reads were aligned to the human reference genome hg38 using HISAT2 (v2.0.4; https://ccb.jhu.edu/ software/hisat2/index.shtml).

After alignment, samples of two individuals were excluded due to low read coverage. Possible mRNA degradation of the remaining samples was assessed by quantifying the 3 ' bias of each gene using mRIN [12]. The summary mRIN values of the samples from the remaining 9 individuals showed no significant RNA degradation $(P$-value $>0.05)$ (Additional file 1 : Table S1) and no correlation between PMD and mRIN values (Additional file 1: Figure S3).

Gene level counts were obtained using HTSeq (v0.6.1; https://github.com/simon-anders/htseq) and the human GTF from Ensembl (release 85; excluding mitochondrialencoded genes). Statistical analyses were performed using the edgeR and limma R/Bioconductor packages [43, 45]. Genes with more than 5 counts in 6 or more samples were retained. Count data were transformed to $\log 2$-counts per million $(\log C P M)$, normalized by applying the trimmed mean of M-values method and precision weighted using voom [30]. Differential expression was assessed using an empirical Bayes moderated t-test within limma's linear model framework including individual as a blocking variable. Resulting $P$-values were corrected for multiple testing using the Benjamini-Hochberg false discovery rate (FDR). Additional gene annotation was retrieved from Ensembl (release 89) using the biomaRt R/Bioconductor package. 
Raw sequence data will be available in the European Genome-Phenome Archive (EGA) and upon request.

Gene set enrichment analysis was performed using CAMERA (limma package) with preset value of 0.01 for the inter-gene correlation using gene set collections Hallmark, C2 (curated), C3 (motifs), C5 (gene ontology), C6 (oncogenic) and C7 (immunologic) retrieved from the Molecular Signatures Database (MSigDB v6.0; Entrez Gene ID version) $[55,64]$. Resulting $P$-values were corrected for multiple testing using the BenjaminiHochberg FDR. For functional annotation of genes related to EC damage the following gene ontology (GO) terms were used: regulation_of_vascular_permeability (go:0043114), response_to_oxidative_stress (go:0006979), inflammatory_response (go:0006954), endothelial_cell_ differentiation (go:0045446), regulation_of_endothelial_ cell_proliferation (go:0001936), regulation_of_cell_adhesion (go:0030155), regulation_of_cellular_response_to_ hypoxia (go:1900037). For functional annotation of genes related to perfusion the following terms were used: regulation_of_blood_pressure (go:0008217), regulation_of_ blood_circulation (go:1903522), mechanosensory_behavior (go:0007638), mechanoreceptor_differentiation (go: 0042490), response_to_fluid_shear_stress (go:0034405). For functional annotation of genes related to cognition the following terms were used: cognition (go:0050890), alzheimers_disease (hsa05010, gse1297), aging_brain (gse1572, gse1572).

\section{RT-qPCR}

For validation of the human samples, qPCR was performed on a BioRad CFX384 machine with the ssoFast EvaGreen method (Biorad). Expression levels of transcripts were obtained with LinRegPCR [41, 46]. Expression levels were normalized against CD31 and vWF expression levels, as these genes are the most stable genes between BA and CCA samples, analyzed with geNorm module of qbase+ [22, 47] (Additional file 1: Figure S1). qPCR on cell culture samples was performed on a BioRad CFX384 machine with the SensiFAST SYBR $^{\circ}$ Green method (Bioline). Expression levels of transcripts were obtained with LinRegPCR $[41,46]$. For the shear stress analysis the transcript levels were normalized against Rplp0 and $\beta$-actin and for the normoxiahypoxia analysis against B2M [35]. All primer sequences are listed in Additional file 1: Table S2.

\section{In vitro cell culture}

The human brain endothelial cell line hCMEC/D3 was kindly provided by Prof. dr. Couraud (Institute Cochin, University Paris Descartes, Paris, France). Cells were grown in EGM-2 medium (Lonza, Basel, Switzerland). Cells were subjected to unidirectional laminar shear stress essentially as described [10], with the following modifications. Cells were cultured on collagen type 1coated parallel plate flow chambers ( $\mu$-Slide I 0.4 luer, Ibidi, Martinsried, Germany) and exposed to calibrated shear stress levels of 10 dyne $/ \mathrm{cm}^{2}$ and 0.74 dyne $/ \mathrm{cm}^{2}$ during 4 days using the Ibidi pump system (Ibidi, Martinsried, Germany). Culturing of cells under hypoxic conditions at $1 \%$ oxygen was performed as described previously [34].

\section{Immunocytochemistry}

For immunocytochemical analysis of the human brain endothelial cell culture, cells were fixated with $4 \%$ paraformaldehyde, permeabilized with $0,1 \%$ Triton in PBS for $10 \mathrm{~min}$ and non-specific binding was blocked with 10\% normal goat serum (X0907, DAKO, Santa Clara, CA, USA) for $30 \mathrm{~min}$. Subsequently cells were incubated overnight at $4{ }^{\circ} \mathrm{C}$ with primary antibodies against CD31 (DAKO, M0823) and HOPX (Invitrogen, PA-72855), SCN3B (Sigma, HPA04707) or DSP (Sdix, 2282.00.02). Secondary antibodies against goatanti-rabbit Alexa633 (Invitrogen, A-21070) and goatanti-mouse IgG1 Alexa568 (Invitrogen, A-21124) together with Hoechst for nuclei staining were incubated for $1 \mathrm{~h}$ at room temperature. The representative images were taking using a Leica TCS SP8 X microscope $(63 x$ objective, Leica Microsystems, Wetzlar, Germany).

\section{Immunohistochemistry}

For immunohistochemical analysis of the human brain microvasculature, $5 \mu \mathrm{m}$ cryosections mounted on coated glass slides (Menzel Gläser Superfrost PLUS, Thermo Scientific, Braunschweig Germany), were airdried and fixated in acetone for $10 \mathrm{~min}$. Sections were incubated for $30 \mathrm{~min}$ with $10 \%$ normal goat serum. Subsequently, sections were incubated overnight at $4{ }^{\circ} \mathrm{C}$ with primary antibodies against HOPX (Invitrogen, PA-72855), SCN3B (Sigma, HPA04707) or DSP (Sdix, 2282.00.02). Subsequently, the secondary antibody goat anti-rabbit Alexa 488 (Life Technologies) was incubated for $1 \mathrm{~h}$. ULEX (Vector Labs) was used as an endothelial cell marker and detected using Alexa 555 labeled streptavidin (Life Technologies). Finally, sections were stained with Hoechst (Molecular Probes) to visualize cellular nuclei and mounted with Mowiol mounting medium. The representative images were taken using a Leica DM6000 microscope (40x objective, Leica Microsystems).

For immunohistochemical analysis of the human BA, $5 \mu \mathrm{m}$ formalin fixed paraffin tissue was mounted on coated glass slides and dewaxed with xylene and rehydrated trough graded ethanol solutions to water. Antigen retrieval was performed at $98^{\circ} \mathrm{C}$ for $20 \mathrm{~min}$ in a Lab 

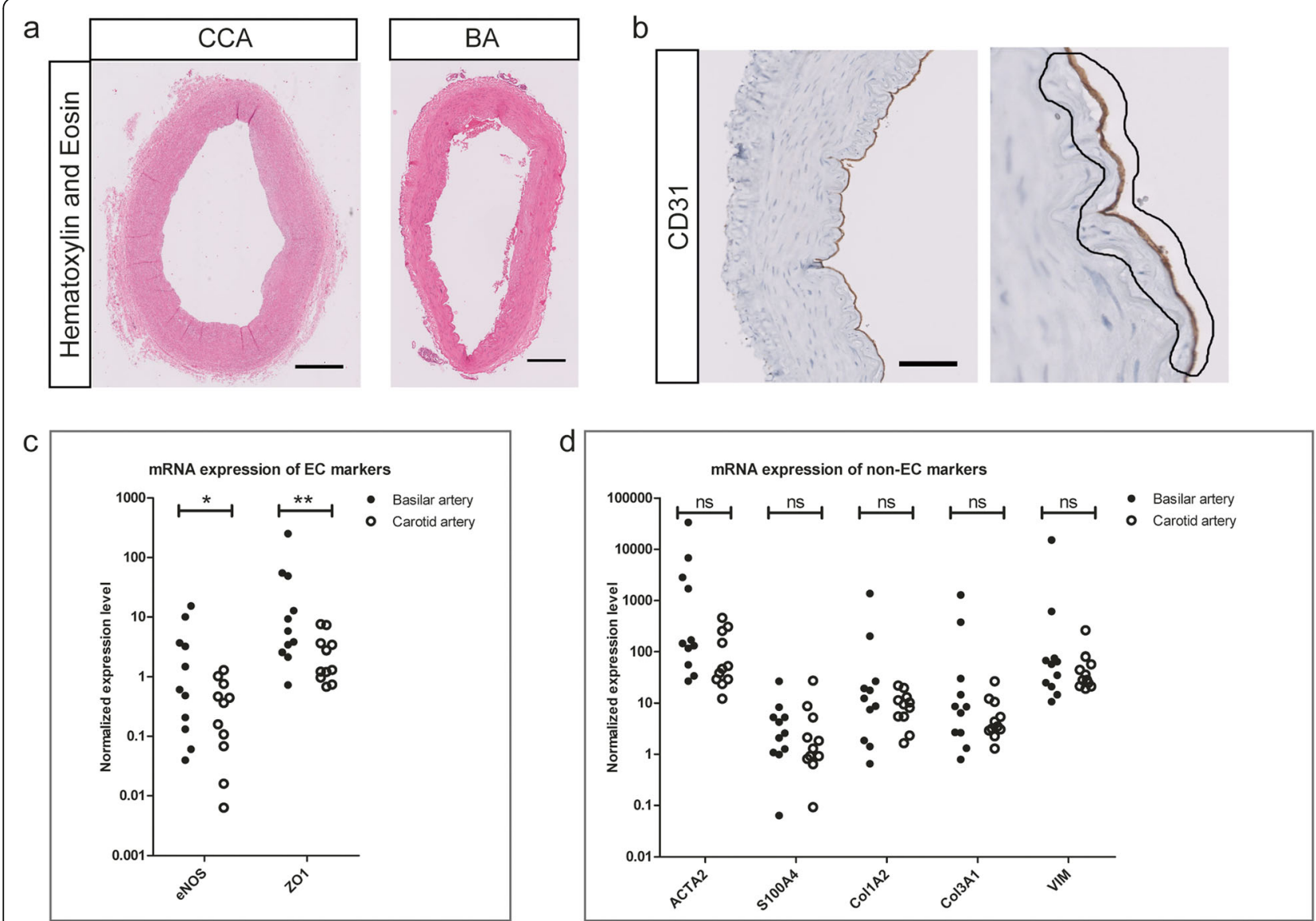

Fig. 1 Laser capture microdissection of macroscopically normal CCA and BA (a) Cross-sections of macroscopically normal CCA and BA, depicted with Hematoxylin and Eosin staining. Scale bar for CCA and BA represents resp. 1200 and $300 \mu \mathrm{m}$. b Vessel wall of BA (left, marked by CD31 in brown, scale bar represents $120 \mu \mathrm{m}$ ) and higher magnification vessel wall (right) with selected area depicting representative LCM cutting margins for EC collection. c Significant differential expression of eNOS and ZO1 between the BA and CCA measured by qPCR. $\mathbf{d}$ No significant difference of smooth muscle cell (ACTA2) and fibroblast (S100A4, Col1A2, Col3A1, VIM) marker expression in LCM-collected population of the BA compared to the CCA samples. $\mathbf{c}, \mathbf{d}$ Data are depicted as expression level normalized against CD31 and vWF. Significance level determined by Wilcoxon signed rank test, $p<0.05\left(^{*}\right)$ and $p<0.01\left(^{* *}\right)$ considered significant. $n=11$ patients. ACTA2 $=$ Actin alpha $2, \operatorname{CD} 31=$ Cluster of differentiation 31 , Col1A2 = Collagen type I alpha 2, Col3A1 = Collagen type III alpha 1, eNOS = endothelial Nitric Oxide Synthase, S100A4=S100 Calcium Binding Protein A4/Fibroblast specific protein 1, VIM = Vimentin, ZO1 = Zona Occludens Protein 1

Vision $^{\text {Tx }}$ PT-module (ThermoFisher) with Tris-EDTA (TA-250-PM4x, ThermoFisher; $\mathrm{pH}=9$ ). The tissue was blocked with Super Block (AAA999, Scytech, Logan, UT, USA) for $10 \mathrm{~min}$ at room temperature. Where after the tissues were incubated with primary antibodies against CD31 (DAKO, M0823) and HOPX (Invitrogen, PA-72855), SCN3B (Sigma, HPA04707) or DSP (Sdix, 2282.00.02) overnight at $4{ }^{\circ} \mathrm{C}$. Secondary antibodies goat-anti-rabbit Alexa633 (Invitrogen, A-21070) and goat-anti-mouse IgG1 Alexa568 (Invitrogen, A-21124) together with Hoechst were applied for $30 \mathrm{~min}$ at room temperature. Sections were mounted with Prolong gold (P36935, ThermoFisher) and representative images were takes using a Leica TCS SP8 X microscope (40x objective, Leica Microsystems, Wetzlar, Germany).

\section{Results}

Laser capture microdissection of human intra- vs. extracranial arterial ECs

Analyses were performed on paired post-mortem derived ECs of the intracranial basilar artery (BA) and the extracranial common carotid artery (CCA). The postmortem samples were derived from 15 individuals with distinct causes of death and age ranging from 32 years to 88 years (Table 1 ). To specifically detect intrinsic differences in gene expression between intra- and extracranial ECs, rather than disease associated characteristics, analyses were performed by comparing macroscopically normal tissues of intra- and extracranial origin within each individual (Fig. 1a). Laser microdissection was used to isolate the ECs (Fig. 1b). 

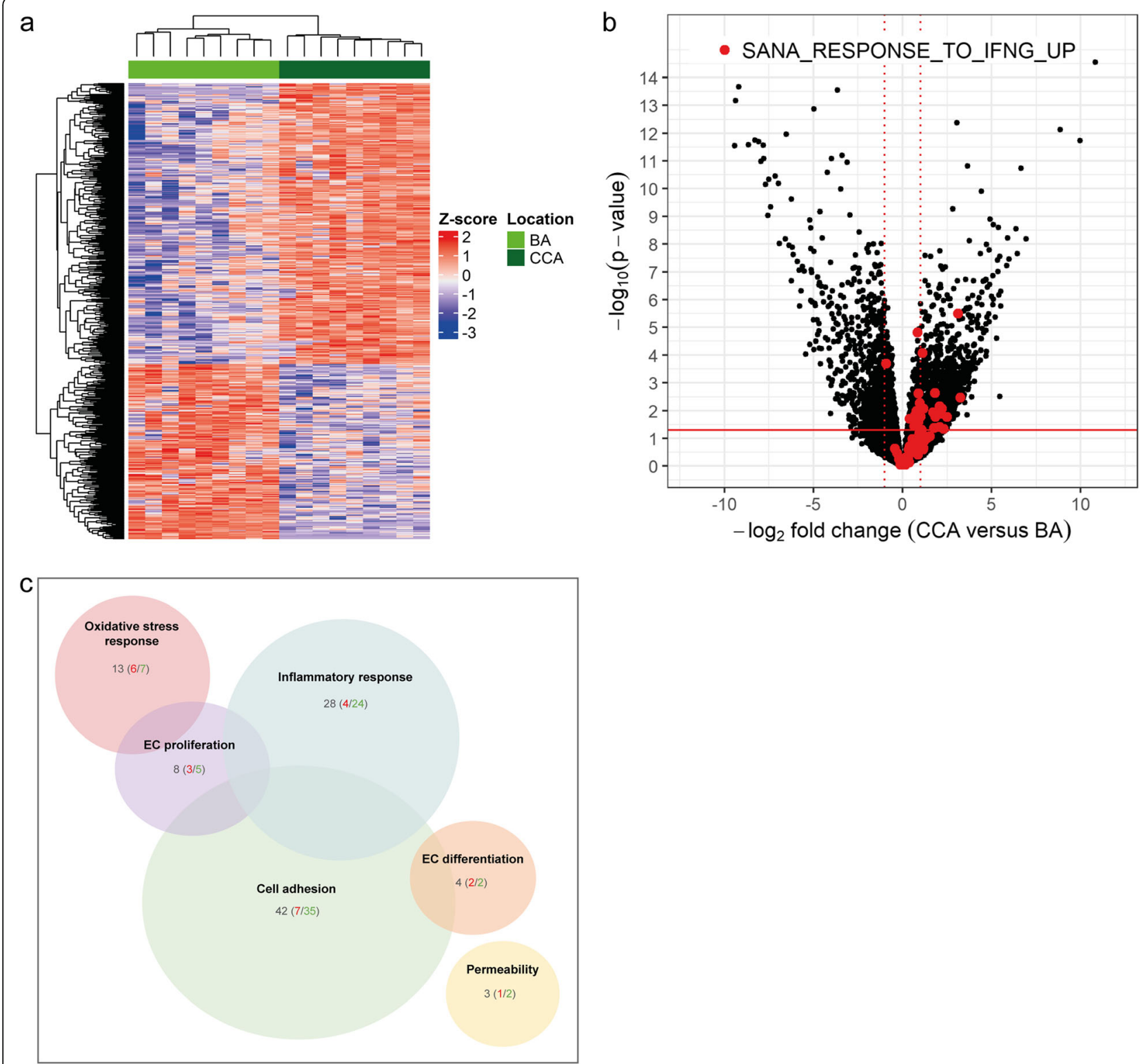

Fig. 2 Differential regulation of immune- and EC damage response genes in the ECs of the BA compared to the CCA (a) Heatmap of the 593 differentially expressed genes (absolute log2-fold-change $>2$ and adjusted $P$-value $<0.05$ ). Dendrogram using Euclidean distance and complete linkage. Color coding corresponds to z-score of logCPM values from blue (downregulated) to red (upregulated). $\mathbf{b}$ Volcano plot with black dots depicting individual genes. In red, genes that were also found to be upregulated by IFNy in a published dataset (MSigDB ID: M4551) [49]. Solid red line corresponds to a P-value $=0.05$. Dotted red lines correspond to an absolute log2-fold-change of 1 . $\mathbf{c}$ Venn diagram with genes related to EC damage response with absolute log2-fold-change $>2$ and $p$-value $<0.05$. Numbers in grey are total genes in subgroup, in red are the genes higher expressed in the BA, in green the genes higher expressed in the CCA

In order to validate the selection of ECs and the differential expression between the BA and the CCA, we performed $\mathrm{qPCR}$ analysis of genes known to be highly expressed in intracranial ECs, such as Zona Occludens 1 (ZO1) and Endothelial Nitric Oxide Synthase 3 (eNOS) $[6,19]$. We found a higher expression of ZO1 and eNOS in the intracranial artery ECs compared to extracranial artery ECs (Fig. 1c), whereas Platelet and Endothelial Cell Adhesion Molecule 1 (PECAM1/CD31) and von
Willebrand factor (vWF) were equally expressed between the two locations (and used as reference genes, Additional file 1: Figure S1).

By selecting the ECs with laser microdissection, our samples could contain a subset of non-endothelial transcripts. To rule out differences in the non-endothelial subpopulation between the BA and the CCA samples, we performed qPCR for several non-endothelial markers. Gene expression of smooth muscle cells and fibroblast 
Table 2 Enrichment of molecular function and cellular component GO-terms in BA and CCA ECs. Top 5 GO molecular function and cellular component terms higher expressed in the BA compared to the CCA and vice versa. FDR is false discovery rate.0020

Gene set enrichment analysis on GO molecular function terms

Top 5 GO-terms higher expressed in basilar artery compared to carotid artery

$\begin{array}{ll}\text { GO-term } & \text { Molecular function } \\ \text { GO:0003735 } & \text { STRUCTURAL_CONSTITUENT_OF_RIBOSOME } \\ \text { GO:0003743 } & \text { TRANSLATION_INITIATION_FACTOR_ACTIVITY } \\ \text { GO:0044822 } & \text { POLY_A_RNA_BINDING } \\ \text { GO:0016675 } & \text { OXIDOREDUCTASE_ACTIVITY_ACTING_ON_A_HEME_GROUP_OF_DONORS } \\ \text { GO:0045182 } & \text { TRANSLATION_REGULATOR_ACTIVITY }\end{array}$

$\begin{array}{ll}P \text {-value } & \text { FDR } \\ 6.27 \mathrm{E}-07 & 3.51 \mathrm{E}-04 \\ 9.51 \mathrm{E}-06 & 2.31 \mathrm{E}-03 \\ 7.67 \mathrm{E}-05 & 9.26 \mathrm{E}-03 \\ 2.00 \mathrm{E}-04 & 1.65 \mathrm{E}-02 \\ 2.11 \mathrm{E}-04 & 1.67 \mathrm{E}-02\end{array}$

Top 5 GO-terms higher expressed in carotid artery compared to basilar artery

$\begin{array}{ll}\text { GO-term } & \text { Molecular function } \\ \text { GO:0042605 } & \text { PEPTIDE_ANTIGEN_BINDING } \\ \text { GO:0008329 } & \text { SIGNALING_PATTERN_RECOGNITION_RECEPTOR_ACTIVITY } \\ \text { GO:0004896 } & \text { CYTOKINE_RECEPTOR_ACTIVITY } \\ \text { GO:0001653 } & \text { PEPTIDE_RECEPTOR_ACTIVITY } \\ \text { GO:0004115 } & \text { 3_5_CYCLIC_AMP_PHOSPHODIESTERASE_ACTIVITY }\end{array}$

Gene set enrichment analysis on GO cellular component terms

Top 5 GO-terms higher expressed in basilar artery compared to carotid artery

\begin{tabular}{|c|c|c|c|}
\hline G0-term & Cellular component & $P$-value & FDR \\
\hline GO:0044391 & RIBOSOMAL_SUBUNIT & 8.67E-08 & 1.02E-04 \\
\hline GO:0022626 & CYTOSOLIC_RIBOSOME & 9.69E-08 & 1.02E-04 \\
\hline GO:0015934 & LARGE_RIBOSOMAL_SUBUNIT & $1.65 \mathrm{E}-07$ & 1.39E-04 \\
\hline GO:0005840 & RIBOSOME & $2.92 \mathrm{E}-07$ & 2.02E-04 \\
\hline GO:0015934 & CYTOSOLIC_LARGE_RIBOSOMAL_SUBUNIT & 2.99E-07 & 2.02E-04 \\
\hline \multicolumn{4}{|c|}{ op 5 GO-terms higher expressed in carotid artery compared to basilar artery } \\
\hline G0-term & Cellular component & $P$-value & FDR \\
\hline GO:0042611 & MHC_PROTEIN_COMPLEX & $1.90 \mathrm{E}-06$ & 7.49E-04 \\
\hline GO:0042613 & MHC_CLASS_IIPROTEIN_COMPLEX & 5.47E-05 & 8.05E-03 \\
\hline GO:0032281 & AMPA_GLUTAMATE_RECEPTOR_COMPLEX & 2.00E-04 & $1.65 \mathrm{E}-02$ \\
\hline GO:0061702 & INFLAMMASOME_COMPLEX & 3.85E-04 & 2.49E-02 \\
\hline GO:0005858 & AXONEMAL_DYNEIN_COMPLEX & 4.33E-04 & 2.63E-02 \\
\hline
\end{tabular}

components was not significantly different between the BA and CCA (Fig. 1d).

\section{An immunoquiescent- and damage protective phenotype of the intracranial artery ECs}

We performed RNA sequencing on the ECs of the BA and CCA of nine individuals. Despite the post-mortem nature, the samples of these nine patients did not show significant RNA degradation $(P$-value $>0.05)$ (Additional file 1: Table S1). Differential gene expression revealed that 900 genes were differentially expressed with absolute $\log 2$ fold-change $>2$ and P-value $<0.05$, and 593 genes were differentially expressed with absolute log2 fold-change $>2$ and adjusted $P$-value $<0.05$ (Fig. 2a). Gene set enrichment analysis on GO molecular function terms showed that proteins encoded by the genes that were expressed to a higher level in the BA ECs are mainly involved in ribosome functioning and translation. In addition, genes higher expressed in the CCA ECs are mainly involved in antigen binding and receptor activity. Furthermore enrichment analysis on GO cellular component terms confirmed enrichment of ribosomal transcripts in the BA, whereas the genes enriched in the CCA are involved in inflammation (Table 2). This analysis indicates that ECs from intracranial and extracranial arteries differ in their molecular functions.

Gene set enrichment analysis also identified a topranked gene set consisting of genes upregulated in primary endothelial cell types (lung, aortic, iliac, dermal, and colon) treated with Interferon-gamma (IFN $\gamma$ ) (MSigDB ID: M4551) [49]. Almost all genes upregulated by IFN $\gamma$ were higher expressed in the extracranial ECs 
compared to the intracranial ECs (Fig. 2b and Additional file 1: Table S3A), which suggests specific regulation of the intracranial ECs resulting in an anti-inflammatory phenotype. This fits with earlier in vitro data showing an immunoquiescent state of brain microvascular ECs [59], supporting the hypothesis that intracranial ECs have a more protective phenotype to resist damage.
To further unravel the molecular pathways involved in the protective nature of the intracranial ECs, we focused on genes involved in EC damage. For this, we analyzed the 900 differentially expressed genes with absolute log2-fold-change $>2$ and $p$-value $<0.05$ (corresponding to adjusted $\mathrm{p}$-value $<0.236$ ) for their involvement in the following EC damage responses: inflammation,
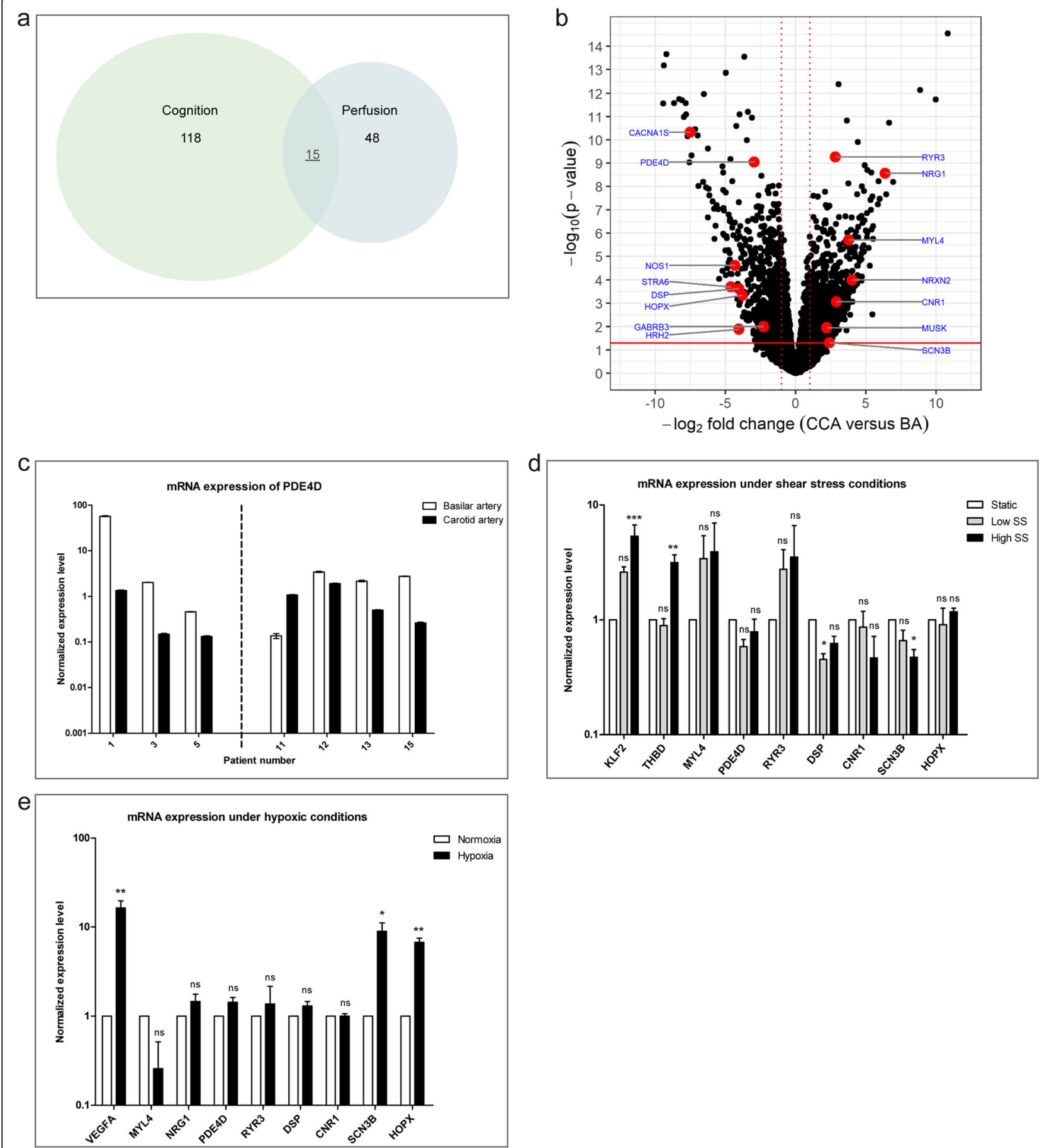

Fig. 3 (See legend on next page.) 


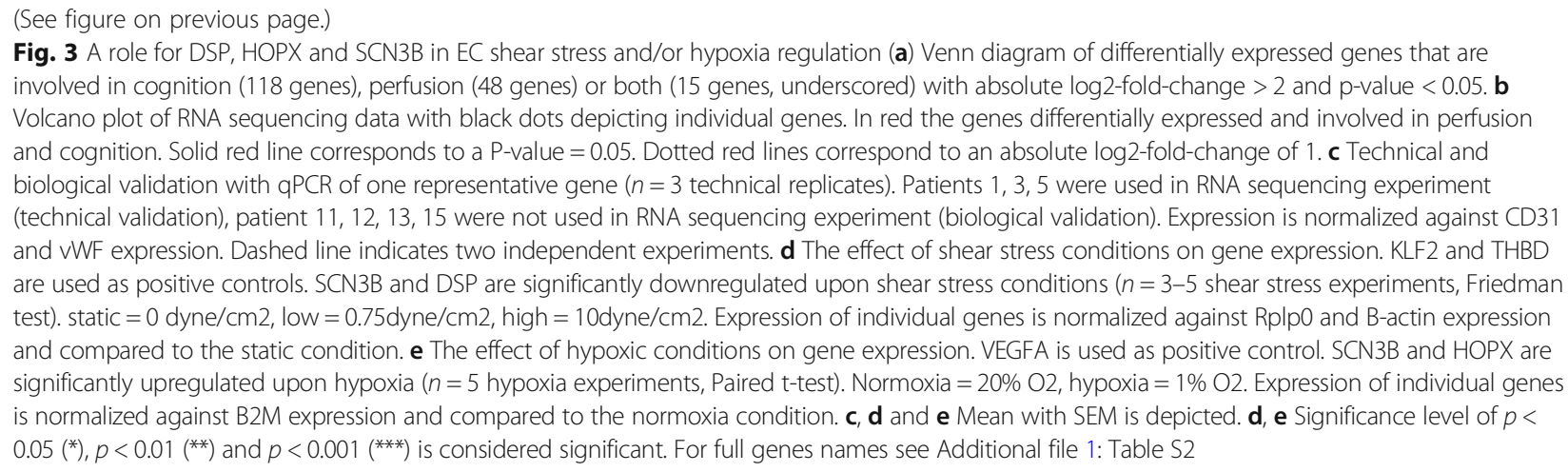

permeability, response to oxidative stress or hypoxia, proliferation, differentiation and cell adhesion (for GO-terms see Materials and Methods section). For almost all of these processes, except for hypoxia responses, several genes were differentially expressed (Fig. $2 \mathrm{c}$ and Additional file 1: Table S3B): 28 genes involved in inflammation, 42 genes in cell adhesion, 3 genes in permeability, 13 genes in oxidative stress, 8 genes in EC proliferation, 4 genes in EC differentiation, suggesting a different response to EC damage in intra- and extracranial ECs. For the inflammatory genes, 24 of the 28 genes did show lower expression levels in the intracranial ECs, as did 35 of the 42 genes involved in cell adhesion, which again fits with the protected state of the intracranial ECs mentioned before. Thus, analysis of our dataset suggests that intracranial artery ECs display protective mechanisms by which an immunoquiescent phenotype is established. In addition, the data show that EC differentiation, permeability and the response to oxidative stress are differentially regulated in intracranial versus extracranial ECs.

\section{Perfusion and cognition-related gene expression in the intracranial artery ECs}

Cerebral circulatory dysfunction is the common nominator for VCI and atherosclerosis. Since the intracranial ECs display a damage protective phenotype, we here investigated whether the intracranial ECs can also exert their protective function upon circulatory dysfunction. For this, we selected a subset of 48 genes matching the GOterms 'blood pressure, blood circulation, mechanosensing and shear stress' (see Materials and Methods) from the 900 differentially expressed genes with absolute $\log 2$-foldchange $>2$ and $p$-value $<0.05$ (corresponding to adjusted $\mathrm{p}$-value $<0.236$ ). Since we were also interested in the involvement of circulatory dysfunction in cerebral function, we additionally selected for the involvement of these genes in 'cognition, Alzheimer's, aging brain' using the homonymous search terms (see Materials and Methods, 118 genes), resulting in a set of 15 genes (Fig. 3a and Additional file 1: Table S3C). Of these 15 genes, eight genes were expressed at a higher level in the BA compared to the CCA and seven genes were expressed at a higher level in the CCA compared to the BA (Fig. 3b). Of these 15 genes, only three (NRG1, NOS1, PDE4D) have already been described for their involvement in EC damage.

To validate the differential expression between intra- and extracranial ECs of these 15 genes known to be involved in perfusion and cognition, we performed quantitative PCR for both technical validation (in three individuals from our RNA sequencing analysis) and biological validation (four individuals not included in our RNA sequencing analysis) (Table 1 for patient characteristics). We could technically and biologically validate the differential expression of five genes (CNR1, GABRB3, PDE4D, RYR3 and STRA6) with qPCR in the majority of individuals (Fig. $3 \mathrm{c}$ and data not shown). The expression of the other genes could not be validated in the human arteries with qPCR due to levels below the qPCR threshold or due to technical reasons.

\section{A novel role for DSP, HOPX and SCN3B in EC shear stress and/or hypoxia responsiveness}

Subsequently we studied the susceptibility of the 15 genes to perfusion in vitro by analyzing their mRNA expression under shear stress and hypoxic conditions. Due to technical reasons or low expression levels of these genes in the in vitro brain ECs, out of the 15 genes, eight genes could be functionally studied further for their susceptibility to hypoxia and seven genes for shear stress (Fig. 3d, e). For shear stress conditions, intracranial ECs were grown under static conditions and under low- and normal shear stress (0.75 dynes $/ \mathrm{cm}^{2}$ and 10 dynes $/ \mathrm{cm}^{2}$, respectively) [3] Shear stress is known to induce an atheroprotective phenotype in ECs [7, 40]. As shear stress increased, the expression of the genes of interest changed; the extracranial more highly expressed gene SCN3B and the intracranial more highly expressed gene DSP were significantly downregulated upon resp. high and low shear stress $(n=5)$ (Fig. $3 \mathrm{~d})$. SCN3B inactivates sodium channels and thereby regulates the action potentials in neurons and myocytes. Low expression of 

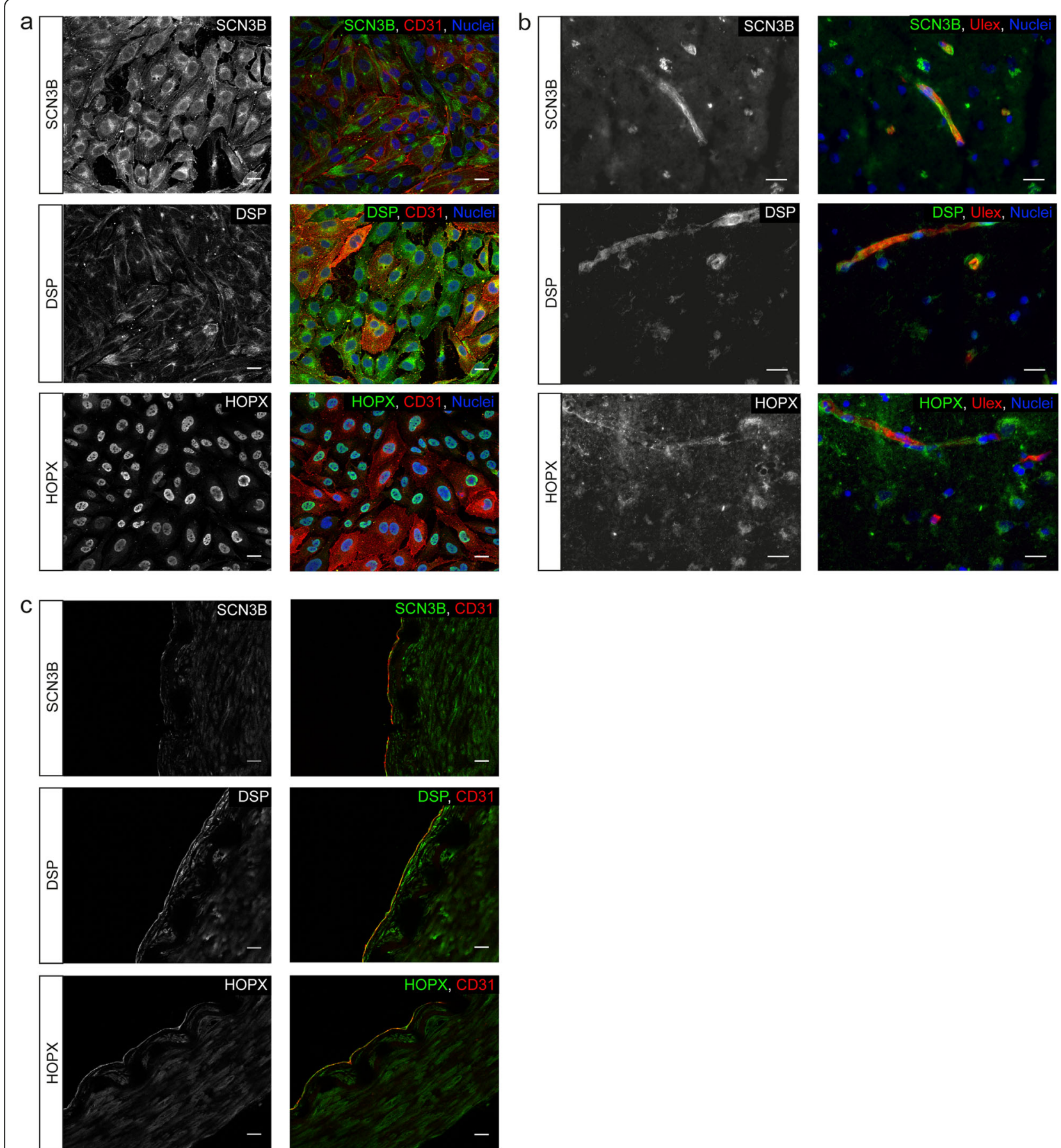

Fig. 4 Expression profile of SCN3B, DSP and HOPX in brain ECs. Localization of DSP, HOPX and SCN3B in (a) human brain ECs in vitro, (b) post-mortem human cortical microvasculature and (c) post-mortem human BA (of one representative patient). SCN3B upper panel, DSP middle panel and HOPX lower panel. Overlay depicts SCN3B, DSP or HOPX in green, ECs in red (CD31 for $\mathbf{a}$ and $\mathbf{c}$, Ulex for $\mathbf{b}$ ) and (a, b) nuclei in blue. $\mathbf{a}, \mathbf{b}$, c Scale bar represents $20 \mu \mathrm{m}$

SCN3B is observed in non-excitable cells, whereas expression in ECs was only detected once before in arterial mouse intracranial ECs, however its physiological role in these non-excitable cells is unclear $[18,54,60]$. Our data suggest a role for SCN3B in human intracranial ECs and elucidate its susceptibility to shear stress. Whereas DSP is known to be involved in adhesion, the function of DSP has not been investigated before in intracranial ECs. Our data suggests that DSP is susceptible to shear stress in intracranial ECs.

We furthermore tested the expression of these genes under hypoxic conditions (1\% O2) and control 
conditions (20\% O2) (Fig. 3e, $n=3-5$ ) [35]. HOPX and SCN3B revealed an increased expression under hypoxic conditions. This showed the responsiveness of SCN3B, not only for shear stress, but also for hypoxia. HOPX was only once detected in the ECs of the cerebral cortex [53], however no physiological role of HOPX in ECs is known. We here revealed the responsiveness of HOPX for hypoxic conditions. With our in vitro data we could demonstrate that SCN3B, DSP and HOPX are responsive to shear stress and/or hypoxia in intracranial ECs, besides being differently regulated in the intracranial ECs compared to the extracranial ECs. These genes were selected for their involvement in cognitive functioning since SCN3B and HOPX were lower expressed and DSP was higher expressed in hippocampal region of patients with Alzheimer's disease [2]. This suggests that these genes may have a function in shear stress and/or hypoxia related cognitive functioning.

\section{A previously unknown expression profile of DSP, HOPX and SCN3B in intracranial ECs}

To investigate the presence of these genes in intracranial ECs in more detail, we studied the protein expression of SCN3B, DSP and HOPX in vitro and in post-mortem brain tissue. Immunocytochemistry of SCN3B, DSP and HOPX in intracranial ECs in vitro showed a perinuclear localization of SCN3B, while DSP and HOPX showed both nuclear as well as perinuclear localization (Fig. 4a). In addition, we further validated the expression of these proteins in post-mortem human brain microvasculature (Fig. 4b) and in the BA of the patients used for RNA sequencing (Fig. 4c and data not shown). Although the expression is not specific for ECs, all three genes are expressed in ECs of the brain. The expression in ECs underscores again the role of these three genes in human brain EC function.

\section{Discussion}

In this study we performed RNA sequencing on human ECs of paired macroscopically normal carotid and basilar arteries. We predominantly detected differential expression of genes involved in immunoquiescence and response to EC damage. Moreover, we discovered the differential expression of genes related to perfusion and cognition in particular SCN3B, HOPX and DSP. Consistently, we show that SCN3B, HOPX and DSP are sensitive to hypoxia and/or shear stress in vitro, suggesting a novel role of these genes in the susceptibility of intracranial ECs to hypoxia and aberrant shear stress, processes involved in vascular cognitive functioning.

In this paper we strengthened the immunoquiescent and revealed a unique damage response phenotype of the intracranial artery ECs, by showing a decreased expression of immune-responsive genes, and different regulation of EC damage-related genes in the intracranial ECs compared to the extracranial ECs. The involvement of the intracranial artery ECs in immunoquiescence and EC damage has not extensively been studied, however cell based assays showed a decrease in immune responsiveness in brain ECs compared to peripheral ECs [59]. Furthermore, it has been reported that human intracranial arteries display a higher anti-oxidant activity compared to extracranial arteries [9]. Besides this limited amount of literature on the intracranial arteries, an extensive amount of research is performed on the intracranial microvasculature. Intracranial ECs of the microvasculature of the brain form a tight barrier between the blood and the underlying brain tissue, known as the blood-brain-barrier. ECs of the brain microvasculature regulate permeability and can maintain an immunoquiescent state. Besides that, cell adhesion, differentiation, proliferation and response to oxidative stress and inflammation are reduced in the ECs of the blood-brain barrier, thereby protecting the brain tissue. This is in accordance with the EC damage phenotype of the BA ECs, which we reported here. However, in our dataset, specific blood-brain-barrier related genes, like $\mathrm{ABC}$-transporters and tight junction proteins, were not differentially expressed in the BA and CCA, except for $\mathrm{ABCB} 1$ and claudin 5 and 10 which were higher expressed in the intracranial artery ECs compared to the extracranial artery ECs. This suggests different expression profiles of the intracranial artery ECs compared to the ECs of the brain microvasculature.

In our data set we revealed the expression of a number of genes yet unknown to be present in intracranial arterial ECs. We found that these genes are not only expressed in arterial ECs but also differentially expressed between the intracranial- and the extracranial arterial ECs. Our data are the first human expression profiling studies of these arteries. Of the 900 differentially expressed genes, we identified 15 genes reported to be involved in both perfusion and cognition. Analyzing these genes upon hypoxia and/or shear stress conditions, resulted in a set of three genes that are differentially expressed in the intracranial ECs, previously linked to cognition and, in the current study, found to play a role in endothelial susceptibility to hypoxia and/or shear stress. One of the key genes we found to be highly expressed in the intracranial ECs compared to the extracranial ECs is DSP. In general, DSP is known to be a major component of desmosomes that facilitate adhesion in epithelial cells, although to date desmosomes have not been described in endothelial cells. On the other hand, DSP was reported to be a component of the complex adherence junction, Complexus adhaerentes, which is present in specific endothelial cells like lymphatic, umbilical vein and lung microvascular endothelial cells $[29,51,58]$. This complex adherence junction consists of E-cadherin, catenins and DSP and is molecularly and structurally different from desmosomes and adherence junctions. Interestingly, loss of DSP causes a weakening of endothelial cell-cell contacts [15]. Although the function of 
DSP in intracranial ECs has not been investigated, its higher expression suggests stronger cell-cell contact between intracranial ECs compared to extracranial ECs, as is also seen in the blood-brain-barrier of the cerebral microvasculature. Decreased expression of DSP upon shear stress in vitro in our endothelial cell cultures suggests a loss of the complex adherence junction upon shear stress. In literature, shear stress results in a reorganization of adherence junctions facilitating the alignment of the ECs [37, 61], which suggests that the complex adherence junctions and/or DSP may also be involved in this reorganization.

Another gene that we found to be highly expressed in the intracranial arterial ECs compared to the extracranial arterial ECs is the transcription factor HOPX. Endothelial expression of HOPX was only reported before in the cerebral cortex [53]. HOPX is known to be expressed in cardiac progenitor cells that will later develop into cardiomyoblasts [25]. Furthermore, HOPX was found to regulate primitive hematopoiesis, however loss of HOPX does not affect endothelial fate specification [39]. Interestingly, HOPX is higher expressed in intracranial ECs compared to extracranial ECs. In more detail, our data showed that HOPX is induced under hypoxic conditions, therefore we suggest a role of HOPX in hypoxic conditions in the intracranial ECs. Since HOPX is a transcription factor, it may be involved in establishing or maintaining the unique intracranial signature upon hypoxic conditions.

Lastly, in our dataset we found SCN3B as a gene differentially expressed in arterial ECs. We detected a decreased expression of SCN3B in intracranial arterial ECs compared to the extracranial arterial ECs (in comparison with DSP and HOPX which were more highly expressed in the intracranial ECs). SCN3B is known to inactivate sodium channels and regulate the action potentials in neurons and myocytes. Sodium channels are mainly present in epithelial cells, however, recent data showed also expression of these channels in ECs [27]. In general, ECs are protected by a glycocalyx that buffers sodium entry into the cell and ECs display a low expression of sodium channels. A damaged glycocalyx and an increase in the expression of sodium channels may facilitate $\mathrm{Na}+$ entry into the ECs, thereby triggering enhanced endothelial permeability [62]. In our data set, we found a lower expression of SCN3B in the intracranial ECs compared to the extracranial ECs, which suggests a different $\mathrm{Na}+$ entry regulation in the intracranial ECs. The decrease of SCN3B upon high shear stress suggests an activation of the sodium channels and an increase in permeability. In addition, the increase of SCN3B in endothelial cells upon hypoxia suggests an inactivation of the sodium channels and thereby a decrease in permeability, which has been documented before for hypoxia [38]. The proposed involvement of these three genes in adhesion and permeability suggests a protective role of the intracranial artery ECs against damage induced by perfusion changes (hypoxia and/or shear stress).

Next to the involvement of these three genes in perfusion, a previous study showed that in the hippocampus of patients with Alzheimer's disease, SCN3B and HOPX are downregulated and DSP is upregulated (sections of left hippocampus, total tissue) [2], suggesting their involvement in cognition. However, the vasculature was not addressed here. In our preliminary data, we could verify this trend in mRNA expression in the brain capillaries of an Alzheimer's disease mouse model (APP/PS1 transgenic mouse model). SCN3B and HOPX seem to be lower expressed, and DSP higher expressed in the brain capillaries of these mice compared to wild type mice (not significant, data not shown). As we postulate here that DSP, SCN3B and HOPX are genes involved in the susceptibility of intracranial ECs against perfusion changes and since we know that they are involved in Alzheimer's disease, further research should focus on the expression of these genes in intracranial ECs of (early and late stage) patients with vascular cognitive disorders. Currently, biomarkers and therapeutic approaches for VCI are missing, due to a lack of understanding of the molecular regulation of $\mathrm{VCI}$ and more specific the EC function in VCI. Since the ECs are key in transferring signals from the blood to the tissue and especially in sensing perfusion changes, we suggest EC molecular targets as key in therapeutic intervention approaches for VCI [21].

Our transcriptome analysis on intracranial artery ECs is based on unique post-mortem material and all analyses were performed per individual rather than in vivo or in vitro models. All published transcriptomic studies on intracranial ECs are restricted to the microvasculature of the brain, and data on the transcriptome of the intracranial artery ECs are lacking, especially in humans. Most studies on the transcriptional regulation of intracranial ECs are performed in mice and focus on the brain microvasculature [15]. The comparison of gene expression in brain microvasculature ECs with ECs from the liver, lung and kidney in mice, revealed a distinct molecular architecture of these EC populations in that only intracranial ECs in the embryonic stage exhibit canonical Wnt signaling [48]. Moreover, seven different vascular beds in the mouse, among which the brain, were used in RNA sequencing, to unravel the transcriptional regulation during development and brain differentiation [24]. Furthermore, single-cell RNA sequencing analysis revealed vascular and vessel-associated cell types in mouse brain and lung, creating a comprehensive molecular dataset for future cell specific research [20]. Recently, the gene expression profile of mural cells, astrocytes, oligodendrocyte precursors, microglia, fibroblast-like cells and the brain endothelial cells 
along the arteriovenous axis in mice was reported, revealing a specific molecular blueprint of the ECs from an arterial to venous origin [60]. In human, isolation of all types of brain cells, including endothelial cells, was performed followed by culturing of these cells for 3 weeks after which single-cell deep sequencing was performed. Gene expression profiles of human astrocytes, microglia, neurons, oligodendrocytes and endothelial cells were determined and differences between murine and human expression profiles were established $[8,52,66]$. In these datasets, both DSP and SCN3B were reported to be expressed in the mouse intracranial ECs, specifically in arterial ECs, whereas HOPX was not detected [20, 24, 60]. However, the comparison of gene expression profiles in human intracranial artery ECs and extracranial ECs and the function of these genes in arterial intracranial ECs was not investigated before.

In our study Amyotrophic Lateral Sclerosis (ALS) patients are overrepresented, since in our institution brain autopsies are more often performed on ALS patients, than on individuals with a non-neurological cause of death. A limitation of our study is that ALS is a genetic driven disease, which may influence our gene analysis [1]. However, we could verify that ALS patients did not have a different expression profile for our genes of interest compared to the non-ALS patients (Additional file 1: Figure S2), although the number of patients for this analysis was low (6 vs. 3 patients). To study the transcriptional profile of the ECs of ALS patients vs. nonneurological controls, an extensive study with more patients and their controls needs to be performed.

The post-mortem nature of the samples used in our study could raise the question if PMD can explain the gene expression differences found in our analysis [13]. The mRIN values of the samples showed no significant RNA degradation (Additional file 1: Table S1). Furthermore, we found no correlation between PMD and mRIN values of the individuals used in our analysis (Additional file 1: Figure S3). Also here, the number of individuals for this correlation is low (11 patients). More individuals should be included for an extensive analysis between PMD and mRIN values. However, the gene expression differences analyzed in our manuscript were performed per individual. Therefore the effect of PMD on gene expression is assumed to be equal between the intracranial and extracranial endothelial cells analyzed. Furthermore, it is suggested that certain tissues, including the brain, have little sensitivity to post-mortem mRNA degradation [67].

With our data we found evidence for a protective phenotype of the human intracranial artery ECs against EC damage thereby they may play a role in vascular cognitive functioning. We furthermore identified three genes, DSP, SCN3B and HOPX, with a previously unknown function in intracranial artery ECs, that are susceptible to hypoxia and/or shear stress. Our data showed that we are able to collect post-mortem ECs with laser capture microdissection that can be used in further functional studies, here in relation to perfusion and cognition, but all studies involved in intracranial ECs can greatly benefit from these data.

\section{Conclusions}

In conclusion, the present profiling study indicates for the first time that human intracranial arterial endothelial cells, compared to extracranial arterial endothelial cells, display a protective phenotype against endothelial damage. Our study highlights the importance of such genes in future studies into their role in the occurence of vascular cognitive impairment.

\section{Supplementary information}

Supplementary information accompanies this paper at https://doi.org/10. 1186/s40478-019-0805-4

\begin{abstract}
Additional file 1: Table S1. mRIN value with z-score and $P$-value for each sample Two samples per patient, first sample derived from BA, second sample derived from CCA. Samples with P-value $>0.05$ were used in RNA sequencing analysis [1]. Table S2. List of primers used in this study Full names with gene symbols and primer sequences used for qPCR analysis. Table S3. Differential expression of genes per gene set analyzed. (A) Gene set consisting of genes upregulated in primary endothelial cell types (lung, aortic, iliac, dermal, and colon) treated with interferongamma (IFNץ) (MSigDB ID: M4551). Almost all genes induced by IFNY were higher expressed in extracranial ECs compared to intracranial ECs. (B) Genes differentially expressed in intracranial ECs and extracranial ECs and involved in EC damage response. Subcategorized for response to oxidative stress, EC proliferation, inflammatory response, cell adhesion, EC differentiation and vascular permeability. (C) 15 genes differentially expressed in intracranial ECs and extracranial ECs and related to perfusion and cognition. LogFC $<0$ is expression elevated in intracranial ECs, logFC $>0$ is elevated in extracranial ECs. Figure S1. Expression stability of reference targets VWF and Pecam1/CD31 are most stable (lowest geNorm M, with $\mathrm{M}$ as gene stability value [2]) between BA and CCA samples ( $n=11$ patients). (1) and (2) refers to different primer pairs. CD34 = cluster of differentiation 34, Cdh5 = cadherin 5, Kdr = Kinase Insert Domain Receptor/ Vascular Endothelial Growth Factor Receptor 2, Pecam = Platelet And Endothelial Cell Adhesion Molecule 1/CD31, Rplp0 = Ribosomal Protein Lateral Stalk Subunit P0, vWF = Von Willebrand Factor. Figure S2. Normalized expression of DSP, HOPX and SCN3B in ALS versus non- ALS patients. Beeswarm plots with the normalized expression (log2CPM) of (a) DSP, (b) HOPX and (c) SCN3B in the BA and CCA samples used for RNA sequencing. No differences between ALS and non-ALS patient are detected. Figure S3. Correlation between PMD and mRIN values. PMD of (a) BA samples and (b) CCA samples ( $n=11$ individuals) correlated to their mRIN values. No significant correlation found for BA and CCA samples. Dots are individuals used in our analysis (see also Table 1 for PMD perindividual).
\end{abstract}

\section{Acknowledgements}

We would like to thank the Amsterdam UMC pathology department and the Netherlands Brain Bank for supplying human brain tissue and the Cellular Imaging core facility in Amsterdam UMC, location AMC and the Advanced Optical Microscopy core facility in Amsterdam UMC, location Vumc O|2 $(\mathrm{AO} \mid 2 \mathrm{M})$ for their expertise of and help with the microscopy applications. Additionally, we would like to thank Wouter Kamphuis for the Alzheimer's disease mouse model and Prof. dr. Peter Hordijk and dr. Pieter Koolwijk for the hypoxia set-up. 


\section{Authors' contributions}

$\mathrm{DH}$ designed and performed the experiments, analyzed the data and wrote the manuscript. OS selected the patients and performed experiments, NW and RF performed and analyzed experiments, AJ and PM performed the RNA sequencing data analysis, CM and IW performed experiments and MD and HV supervised the project. All authors read and approved the final manuscript.

\section{Funding}

We acknowledge the support from the Netherlands CardioVascular Research Initiative: the Dutch Heart Foundation (CVON 2012-06 Heart Brain. Connection and CVON 2018-28 Heart Brain Connection - crossroads), Dutch Federation of University Medical Centers, the Netherlands Organization for Health Research and Development and the Royal Netherlands Academy of Science. Furthermore we acknowledge Amsterdam Cardiovascular Sciences for their financial support in the 'Out of-the-box' Alliantie Call 2017.

\section{Availability of data and materials}

The datasets used and analyzed during the current study is available from the corresponding author on request and will be available in the European Genome-Phenome Archive (EGA) upon publication.

\section{Ethics approval and consent to participate}

The criteria for the code of proper secondary use of human tissue in the Netherlands were met [Human tissue and medical research: code of conduct for responsible use. Federation of Dutch Medical Scientific Societies] and written permission to obtain the materials at autopsy for research purposes was granted by the family of the patients.

\section{Consent for publication}

Not applicable.

\section{Competing interests}

The authors declare that they have no competing interests.

\section{Author details}

'Department of Pathology, Amsterdam UMC, University of Amsterdam, Amsterdam Cardiovascular Sciences, Meibergdreef 9, Amsterdam, Netherlands. ${ }^{2}$ Department of Molecular Cell Biology and Immunology, Amsterdam UMC, Vrije Universiteit Amsterdam, Amsterdam Neuroscience, de Boelelaan, 1117 Amsterdam, Netherlands. ${ }^{3}$ Department of Clinical Epidemiology, Biostatistics and Bioinformatics; Amsterdam Public Health, Amsterdam UMC, University of Amsterdam, Meibergdreef 9, Amsterdam, Netherlands.

Received: 26 July 2019 Accepted: 7 September 2019 Published online: 14 October 2019

\section{References}

1. Al-Chalabi A, Jones A, Troakes C, King A, Al-Sarraj S, van den Berg LH (2012) The genetics and neuropathology of amyotrophic lateral sclerosis. Acta Neuropathol 124:339-352. https://doi.org/10.1007/s00401-012-1022-4

2. Blalock EM, Geddes JW, Chen KC, Porter NM, Markesbery WR, Landfield PW (2004) Incipient Alzheimer's disease: microarray correlation analyses reveal major transcriptional and tumor suppressor responses. Proc Natl Acad Sci U S A 101:2173-2178. https://doi.org/10.1073/pnas.0308512100

3. Boon RA, Leyen TA, Fontijn RD, Fledderus JO, Baggen JM, Volger OL, van Nieuw Amerongen GP, Horrevoets AJ (2010) KLF2-induced actin shear fibers control both alignment to flow and JNK signaling in vascular endothelium. Blood 115:2533-2542. https://doi.org/10.1182/blood-2009-06-228726

4. Bos D, Vernooij MW, de Bruijn RF, Koudstaal PJ, Hofman A, Franco OH, van der Lugt A, Ikram MA (2015) Atherosclerotic calcification is related to a higher risk of dementia and cognitive decline. Alzheimers Dement 11:639647 e631. https://doi.org/10.1016/.j.jalz.2014.05.1758

5. Carcaillon L, Plichart M, Zureik M, Rouaud O, Majed B, Ritchie K, Tzourio C, Dartigues JF, Empana JP (2015) Carotid plaque as a predictor of dementia in older adults: the Three-City study. Alzheimers Dement 11:239-248. https://doi.org/10.1016/j.jalz.2014.07.160

6. Citi S, Cordenonsi M (1998) Tight junction proteins. Biochim Biophys Acta 1448:1-11

7. Dai G, Kaazempur-Mofrad MR, Natarajan S, Zhang Y, Vaughn S, Blackman BR, Kamm RD, Garcia-Cardena G, Gimbrone MA Jr (2004) Distinct endothelial phenotypes evoked by arterial waveforms derived from atherosclerosissusceptible and -resistant regions of human vasculature. Proc Natl Acad Sci U S A 101:14871-14876. https://doi.org/10.1073/pnas.0406073101

8. Darmanis S, Sloan SA, Zhang Y, Enge M, Caneda C, Shuer LM, Hayden Gephart MG, Barres BA, Quake SR (2015) A survey of human brain transcriptome diversity at the single cell level. Proc Natl Acad Sci U S A 112: 7285-7290. https://doi.org/10.1073/pnas.1507125112

9. D'Armiento FP, Bianchi A, de Nigris F, Capuzzi DM, D'Armiento MR, Crimi G, Abete P, Palinski W, Condorelli M, Napoli C (2001) Age-related effects on atherogenesis and scavenger enzymes of intracranial and extracranial arteries in men without classic risk factors for atherosclerosis. Stroke 32:2472-2479

10. Dekker RJ, van Soest S, Fontijn RD, Salamanca S, de Groot PG, VanBavel E, Pannekoek H, Horrevoets AJ (2002) Prolonged fluid shear stress induces a distinct set of endothelial cell genes, most specifically lung Kruppel-like factor (KLF2). Blood 100:1689-1698. https://doi.org/10.1182/blood-2002-01-0046

11. Dixit NK, Vazquez LD, Cross NJ, Kuhl EA, Serber ER, Kovacs A, Dede DE, Conti JB, Sears SF (2010) Cardiac resynchronization therapy: a pilot study examining cognitive change in patients before and after treatment. Clin Cardiol 33:84-88. https://doi.org/10.1002/clc.20710

12. Feng $H$, Zhang $X$, Zhang C (2015) mRIN for direct assessment of genomewide and gene-specific mRNA integrity from large-scale RNA-sequencing data. Nat Commun 6:7816. https://doi.org/10.1038/ncomms8816

13. Ferreira PG, Munoz-Aguirre M, Reverter F, Sa Godinho CP, Sousa A, Amadoz A, Sodaei R, Hidalgo MR, Pervouchine D, Carbonell-Caballero J, Nurtdinov R, Breschi A, Amador R, Oliveira P, Cubuk C, Curado J, Aguet F, Oliveira C, Dopazo J, Sammeth M, Ardlie KG, Guigo R (2018) The effects of death and post-mortem cold ischemia on human tissue transcriptomes. Nat Commun 9:490. https://doi.org/10.1038/s41467-017-02772-x

14. Frances A, Sandra O, Lucy U (2016) Vascular cognitive impairment, a cardiovascular complication. World J Psychiatry 6:199-207. https://doi.org/ 10.5498/wjp.v6.i2.199

15. Gallicano Gl, Bauer C, Fuchs E (2001) Rescuing desmoplakin function in extraembryonic ectoderm reveals the importance of this protein in embryonic heart, neuroepithelium, skin and vasculature. Development 128:929-941

16. Gorelick PB, Scuteri A, Black SE, Decarli C, Greenberg SM, ladecola C, Launer LJ, Laurent S, Lopez OL, Nyenhuis D, Petersen RC, Schneider JA, Tzourio C, Arnett DK, Bennett DA, Chui HC, Higashida RT, Lindquist R, Nilsson PM, Roman GC, Sellke FW, Seshadri S, American Heart Association Stroke Council CoE, Prevention CoCNCoCR, Intervention, Council on Cardiovascular S, Anesthesia (2011) Vascular contributions to cognitive impairment and dementia: a statement for healthcare professionals from the american heart association/american stroke association. Stroke 42:2672-2713. https://doi. org/10.1161/STR.0b013e3182299496

17. Gorelick PB, Wong KS, Bae HJ, Pandey DK (2008) Large artery intracranial occlusive disease: a large worldwide burden but a relatively neglected frontier. Stroke 39:2396-2399. https:/doi.org/10.1161/STROKEAHA.107.505776

18. Hakim P, Brice N, Thresher R, Lawrence J, Zhang Y, Jackson AP, Grace AA, Huang CL (2010) Scn3b knockout mice exhibit abnormal sino-atrial and cardiac conduction properties. Acta Physiol (Oxf) 198:47-59. https://doi.org/ 10.1111/j.1748-1716.2009.02048.x

19. Hariharan A, Jing Y, Collie ND, Zhang H, Liu P (2019) Altered neurovascular coupling and brain arginine metabolism in endothelial nitric oxide synthase deficient mice. Nitric Oxide 87:60-72. https://doi.org/10.1016/..niox.2019.03.006

20. He L, Vanlandewijck M, Mae MA, Andrae J, Ando K, Del Gaudio F, Nahar K, Lebouvier T, Lavina B, Gouveia L, Sun Y, Raschperger E, Segerstolpe A, Liu J, Gustafsson S, Rasanen M, Zarb Y, Mochizuki N, Keller A, Lendahl U, Betsholtz C (2018) Single-cell RNA sequencing of mouse brain and lung vascular and vesselassociated cell types. Sci Data 5:180160. https://doi.org/10.1038/sdata.2018.160

21. Helbing T, Olivier C, Bode C, Moser M, Diehl P (2014) Role of microparticles in endothelial dysfunction and arterial hypertension. World I Cardiol 6: 1135-1139. https://doi.org/10.4330/wjc.v6.i11.1135

22. Hellemans J, Mortier G, De Paepe A, Speleman F, Vandesompele J (2007) qBase relative quantification framework and software for management and automated analysis of real-time quantitative PCR data. Genome Biol 8:R19. https://doi.org/10.1186/gb-2007-8-2-r19

23. Hoth KF, Poppas A, Ellison KE, Paul RH, Sokobin A, Cho Y, Cohen RA (2010) Link between change in cognition and left ventricular function following cardiac resynchronization therapy. J Cardiopulm Rehabil Prev 30:401-408. https://doi.org/10.1097/HCR.0b013e3181e1739a

24. Hupe M, Li MX, Kneitz S, Davydova D, Yokota C, Kele J, Hot B, Stenman JM, Gessler M (2017) Gene expression profiles of brain endothelial cells during 
embryonic development at bulk and single-cell levels. Sci Signal 10. https:// doi.org/10.1126/scisignal.aag2476

25. Jain R, Li D, Gupta M, Manderfield LJ, Ifkovits JL, Wang Q, Liu F, Liu Y, Poleshko A, Padmanabhan A, Raum JC, Li L, Morrisey EE, Lu MM, Won KJ, Epstein JA (2015) HEART DEVELOPMENT. Integration of Bmp and Wnt signaling by Hopx specifies commitment of cardiomyoblasts. Science 348: aaa6071. https://doi.org/10.1126/science.aaa6071

26. Jellinger KA (2014) Pathogenesis and treatment of vascular cognitive impairment Neurodegener Dis Manag 4:471-490. https:/doi.org/10.2217/nmt.14.37

27. Jia G, Habibi J, Aroor AR, Hill MA, DeMarco VG, Lee LE, Ma L, Barron BJ, Whaley-Connell A, Sowers JR (2018) Enhanced endothelium epithelial sodium channel signaling prompts left ventricular diastolic dysfunction in obese female mice. Metabolism 78:69-79. https://doi.org/10.1016/j.metabol. 2017.08.008

28. Keil JM, Qalieh A, Kwan KY (2018) Brain transcriptome databases: a user's guide. J Neurosci. https://doi.org/10.1523/JNEUROSCl.1930-17.2018

29. Kowalczyk AP, Navarro P, Dejana E, Bornslaeger EA, Green KJ, Kopp DS, Borgwardt JE (1998) VE-cadherin and desmoplakin are assembled into dermal microvascular endothelial intercellular junctions: a pivotal role for plakoglobin in the recruitment of desmoplakin to intercellular junctions. J Cell Sci 111 ( Pt 20:3045-3057

30. Law CW, Chen Y, Shi W, Smyth GK (2014) Voom: precision weights unlock linear model analysis tools for RNA-seq read counts. Genome Biol 15:R29. https://doi.org/10.1186/gb-2014-15-2-r29

31. Mathur KS, Kashyap SK, Mathur SC (1968) Distribution and severity of atherosclerosis of aorta, coronary and cerebral arteries in persons dying without morphologic evidence of atherosclerotic catastrophe in North India. A study of 900 autopsies. J Assoc Physicians India 16:113-122

32. Matsushima W, Herzog VA, Neumann T, Gapp K, Zuber J, Ameres SL, Miska EA (2018) SLAM-ITseq: sequencing cell type-specific transcriptomes without cell sorting. Development 145. https://doi.org/10.1242/dev.164640

33. Moossy J (1966) Morphology, sites and epidemiology of cerebral atherosclerosis. Res Publ Assoc Res Nerv Ment Dis 41:1-22

34. Nauta TD, Duyndam MC, Weijers EM, van Hinsbergh VM, Koolwijk P (2016) HIF-2alpha expression regulates sprout formation into 3D fibrin matrices in prolonged hypoxia in human microvascular endothelial cells. PLoS One 11: e0160700. https://doi.org/10.1371/journal.pone.0160700

35. Nauta TD, van den Broek M, Gibbs S, van der Pouw-Kraan TC, Oudejans CB, van Hinsbergh WW, Koolwijk P (2017) Identification of HIF-2alpha-regulated genes that play a role in human microvascular endothelial sprouting during prolonged hypoxia in vitro. Angiogenesis 20:39-54. doi:https://doi.org/10. 1007/s10456-016-9527-4

36. Newman AB, Fitzpatrick AL, Lopez O, Jackson S, Lyketsos C, Jagust W, Ives D, Dekosky ST, Kuller LH (2005) Dementia and Alzheimer's disease incidence in relationship to cardiovascular disease in the cardiovascular health study cohort. J Am Geriatr Soc 53:1101-1107. https://doi.org/10.1111/j.1532-5415.2005.53360.x

37. Noria S, Cowan DB, Gotlieb Al, Langille BL (1999) Transient and steady-state effects of shear stress on endothelial cell adherens junctions. Circ Res 85:504-514

38. Page S, Munsell A, Al-Ahmad AJ (2016) Cerebral hypoxia/ischemia selectively disrupts tight junctions complexes in stem cell-derived human brain microvascular endothelial cells. Fluids Barriers CNS 13:16. https://doi. org/10.1186/s12987-016-0042-1

39. Palpant NJ, Wang $Y$, Hadland B, Zaunbrecher RJ, Redd M, Jones D, Pabon L, Jain R, Epstein J, Ruzzo WL, Zheng Y, Bernstein I, Margolin A, Murry CE (2017) Chromatin and transcriptional analysis of mesoderm progenitor cells identifies HOPX as a regulator of primitive hematopoiesis. Cell Rep 20:15971608. https://doi.org/10.1016/j.celrep.2017.07.067

40. Passerini AG, Polacek DC, Shi C, Francesco NM, Manduchi E, Grant GR, Pritchard WF, Powell S, Chang GY, Stoeckert CJ Jr, Davies PF (2004) Coexisting proinflammatory and antioxidative endothelial transcription profiles in a disturbed flow region of the adult porcine aorta. Proc Natl Acad Sci U S A 101:2482-2487. https://doi.org/10.1073/pnas.0305938101

41. Ramakers C, Ruijter JM, Deprez RH, Moorman AF (2003) Assumption-free analysis of quantitative real-time polymerase chain reaction (PCR) data. Neurosci Lett 339:62-66

42. Reitz C, Luchsinger JA (2007) Relation of blood pressure to cognitive impairment and dementia. Curr Hypertens Rev 3:166-176. https://doi.org/ 10.2174/157340207781386747

43. Ritchie ME, Phipson B, Wu D, Hu Y, Law CW, Shi W, Smyth GK (2015) Limma powers differential expression analyses for RNA-sequencing and microarray studies. Nucleic Acids Res 43:e47. https:/doi.org/10.1093/nar/gkv007
44. Ritz K, Denswil NP, Stam OC, van Lieshout JJ, Daemen MJ (2014) Cause and mechanisms of intracranial atherosclerosis. Circulation 130:1407-1414. https://doi.org/10.1161/CIRCULATIONAHA.114.011147

45. Robinson MD, McCarthy DJ, Smyth GK (2010) edgeR: a Bioconductor package for differential expression analysis of digital gene expression data. Bioinformatics 26:139-140. https://doi.org/10.1093/bioinformatics/btp616

46. Ruijter JM, Ramakers C, Hoogaars WM, Karlen Y, Bakker O, van den Hoff MJ, Moorman AF (2009) Amplification efficiency: linking baseline and bias in the analysis of quantitative PCR data. Nucleic Acids Res 37:e45. https://doi.org/ 10.1093/nar/gkp045

47. Ruiz-Villalba A, Mattiotti A, Gunst QD, Cano-Ballesteros S, van den Hoff MJ, Ruijter JM (2017) Reference genes for gene expression studies in the mouse heart. Sci Rep 7:24. https://doi.org/10.1038/s41598-017-00043-9

48. Sabbagh MF, Heng JS, Luo C, Castanon RG, Nery JR, Rattner A, Goff LA, Ecker JR, Nathans I (2018) Transcriptional and epigenomic landscapes of CNS and nonCNS vascular endothelial cells. Elife 7. https://doi.org/10.7554/eLife.36187

49. Sana TR, Janatpour MJ, Sathe M, McEvoy LM, McClanahan TK (2005) Microarray analysis of primary endothelial cells challenged with different inflammatory and immune cytokines. Cytokine 29:256-269. https://doi.org/ 10.1016/j.cyto.2004.11.003

50. Sayols S, Scherzinger D, Klein H (2016) dupRadar: a Bioconductor package for the assessment of PCR artifacts in RNA-Seq data. BMC Bioinformatics 17: 428. https://doi.org/10.1186/s12859-016-1276-2

51. Schmelz M, Franke WW (1993) Complexus adhaerentes, a new group of desmoplakin-containing junctions in endothelial cells: the syndesmos connecting retothelial cells of lymph nodes. Eur J Cell Biol 61:274-289

52. Spaethling JM, Na YJ, Lee J, Ulyanova AV, Baltuch GH, Bell TJ, Brem S, Chen HI, Dueck H, Fisher SA, Garcia MP, Khaladkar M, Kung DK, Lucas TH Jr. O'Rourke DM, Stefanik D, Wang J, Wolf JA, Bartfai T, Grady MS, Sul JY, Kim J, Eberwine JH (2017) Primary cell culture of live Neurosurgically resected aged adult human brain cells and single cell transcriptomics. Cell Rep 18: 791-803. https://doi.org/10.1016/..celrep.2016.12.066

53. Stadler C, Rexhepaj E, Singan VR, Murphy RF, Pepperkok R, Uhlen M, Simpson JC, Lundberg E (2013) Immunofluorescence and fluorescent-protein tagging show high correlation for protein localization in mammalian cells. Nat Methods 10:315-323. https://doi.org/10.1038/nmeth.2377

54. Stevens EB, Cox PJ, Shah BS, Dixon AK, Richardson PJ, Pinnock RD, Lee K (2001) Tissue distribution and functional expression of the human voltagegated sodium channel beta3 subunit. Pflugers Arch 441:481-488

55. Subramanian A, Tamayo P, Mootha VK, Mukherjee S, Ebert BL, Gillette MA, Paulovich A, Pomeroy SL, Golub TR, Lander ES, Mesirov JP (2005) Gene set enrichment analysis: a knowledge-based approach for interpreting genomewide expression profiles. Proc Natl Acad Sci U S A 102:15545-15550. https:// doi.org/10.1073/pnas.0506580102

56. Suhy AM, Webb A, Papp AC, Geier EG, Sadee W (2017) Expression and splicing of $A B C$ and SLC transporters in the human blood-brain barrier measured with RNAseq. Eur J Pharm Sci 103:47-51. https://doi.org/10.1016/j.ejps.2017.02.010

57. Uehara T, Tabuchi M, Mori E (1998) Frequency and clinical correlates of occlusive lesions of cerebral arteries in Japanese patients without stroke. Evaluation by MR angiography. Cerebrovasc Dis 8:267-272. https://doi.org/ $10.1159 / 000015864$

58. Valiron O, Chevrier V, Usson Y, Breviario F, Job D, Dejana E (1996) Desmoplakin expression and organization at human umbilical vein endothelial cell-to-cell junctions. J Cell Sci 109 ( Pt 8:2141-2149

59. van Doorn R, Lopes Pinheiro MA, Kooij G, Lakeman $K$, van het Hof B, van der Pol SM, Geerts D, van Horssen J, van der Valk P, van der Kam E, Ronken E, Reijerkerk A, de Vries HE (2012) Sphingosine 1-phosphate receptor 5 mediates the immune quiescence of the human brain endothelial barrier. J Neuroinflammation 9:133. https://doi.org/10.1186/1742-2094-9-133

60. Vanlandewijck M, He L, Mae MA, Andrae J, Ando K, Del Gaudio F, Nahar K, Lebouvier T, Lavina B, Gouveia L, Sun Y, Raschperger E, Rasanen M, Zarb Y, Mochizuki N, Keller A, Lendahl U, Betsholtz C (2018) A molecular atlas of cell types and zonation in the brain vasculature. Nature 554:475-480. https://doi. org/10.1038/nature25739

61. Walsh TG, Murphy RP, Fitzpatrick P, Rochfort KD, Guinan AF, Murphy A, Cummins PM (2011) Stabilization of brain microvascular endothelial barrier function by shear stress involves VE-cadherin signaling leading to modulation of pTyr-occludin levels. J Cell Physiol 226:3053-3063. https://doi. org/10.1002/jcp.22655

62. Warnock DG, Kusche-Vihrog K, Tarjus A, Sheng S, Oberleithner H, Kleyman TR, Jaisser F (2014) Blood pressure and amiloride-sensitive sodium channels 
in vascular and renal cells. Nat Rev Nephrol 10:146-157. https://doi.org/10. 1038/nrneph.2013.275

63. Wendell CR, Waldstein SR, Ferrucci L, O'Brien RJ, Strait JB, Zonderman AB (2012) Carotid atherosclerosis and prospective risk of dementia. Stroke 43: 3319-3324. https://doi.org/10.1161/STROKEAHA.112.672527

64. Wu D, Smyth GK (2012) Camera: a competitive gene set test accounting for inter-gene correlation. Nucleic Acids Res 40:e133. https://doi.org/10.1093/ nar/gks461

65. Yarchoan M, Xie SX, Kling MA, Toledo JB, Wolk DA, Lee EB, Van Deerlin V, Lee VM, Trojanowski JQ, Arnold SE (2012) Cerebrovascular atherosclerosis correlates with Alzheimer pathology in neurodegenerative dementias. Brain 135:3749-3756. https://doi.org/10.1093/brain/aws271

66. Zhang Y, Sloan SA, Clarke LE, Caneda C, Plaza CA, Blumenthal PD, Vogel H, Steinberg GK, Edwards MS, Li G, Duncan JA 3rd, Cheshier SH, Shuer LM, Chang EF, Grant GA, Gephart MG, Barres BA (2016) Purification and characterization of progenitor and mature human astrocytes reveals transcriptional and functional differences with mouse. Neuron 89:37-53. https://doi.org/10.1016/..neuron.2015.11.013

67. Zhu Y, Wang L, Yin Y, Yang E (2017) Systematic analysis of gene expression patterns associated with postmortem interval in human tissues. Sci Rep 7: 5435. https://doi.org/10.1038/s41598-017-05882-0

\section{Publisher's Note}

Springer Nature remains neutral with regard to jurisdictional claims in published maps and institutional affiliations.

Ready to submit your research? Choose BMC and benefit from:

- fast, convenient online submission

- thorough peer review by experienced researchers in your field

- rapid publication on acceptance

- support for research data, including large and complex data types

- gold Open Access which fosters wider collaboration and increased citations

- maximum visibility for your research: over $100 \mathrm{M}$ website views per year

At $\mathrm{BMC}$, research is always in progress.

Learn more biomedcentral.com/submissions 